\title{
A macro-element to simulate dynamic Soil-Structure Interaction
}

\author{
Stéphane Grange*, Panagiotis Kotronis, Jacky Mazars \\ Laboratoire 3S-R (Sols, Solides, Structures-Risques) INPG/UJF/CNRS, Domaine Universitaire BP 53, 38041 Grenoble cedex 9, France
}

This paper presents a macro-element to simulate dynamic Soil-Structure Interaction (SSI). This new numerical tool is suitable for dynamic (seismic) loadings on structures with shallow foundations. It takes into account the plasticity of the soil, the uplift of the foundation, $P-\theta$ effects and the radiation damping. The foundation is supposed infinitely rigid while its movement is entirely described by a system of global variables (forces and displacements) defined in its center. The nonlinear behavior of the soil and the uplift of the foundation are reproduced using the classical theory of plasticity. Uplift and plasticity are combined using the theory of multi-mechanisms. Failure is described by an interaction diagram of the ultimate bearing capacity of the foundation under combined loads. The performance of the macro-element is validated using the experimental results of the structure Camus IV. Furthermore, a parametric study on the behavior of a seven-story building shows the capability of the macro-element to consider different types of soils. Based on the results obtained it seems now possible to use this approach to investigate numerically the behavior of a wider variety of configurations.

\section{Introduction}

In structural engineering one has often to consider Soil-Structure Interaction (SSI). For example when designing slender structures like tall buildings or bridge piers, it is necessary to define the characteristics of the soil, the structure and the nature of the connection between them. It is obvious that the behavior will be different if the structure is embedded in the soil or just connected with a knee joint.

Simulating SSI involves detailed 3D meshes for the soil and the structure, a big number of degrees of freedom and thus huge computational costs. This is the reason why simplified modeling strategies have extensively been developed during recent years. Among them, the "macro-element" approach consists in condensing all nonlinearities into a finite domain ("close field") and works with generalized variables (forces and displacements) at the center of the foundation. In that way it allows considerably decreasing the necessary degrees of freedom of the numerical model.

Several macro-elements can be found in the literature [1-13]. The macro-element presented in [14-17] reproduces the behavior of a 3D shallow foundation of circular, rectangular or strip shape, submitted to cyclic loadings. It takes into account the plasticity of the soil and the uplift of the foundation. An extension of this macroelement for dynamic loadings is introduced hereafter considering radiation damping, but also $P-\theta$ effects (second order effects due to

\footnotetext{
* Corresponding author.

E-mail addresses: Stephane.Grange@hmg.inpg.fr (S. Grange),

Panagiotis.Kotronis@hmg.inpg.fr (P. Kotronis), Jacky.Mazars@inpg.fr (J. Mazars).
}

the rotation of the foundation). It is implemented into FEDEASLab, a finite element MATLAB toolbox [18].

The performance of the macro-element is validated using the experimental results of the Camus IV structure, a reinforced concrete fifth-story building tested on the shaking table of CEA Saclay [19-21]. Furthermore, a parametric study on the behavior of a reinforced concrete seven-story building tested on the new NEES Large High-Performance Outdoor Shake Table [22], shows the capability of the macro-element to simulate SSI for different types of soils.

\section{General description of the macro-element}

This section describes briefly the three mechanisms taken into account by the macro-element (elasticity, plasticity of the soil and uplift of the foundation). For more information the reader is invited to look in [14-17]. In Sections 3 and 4 the extension of the macroelement for dynamic loadings (radiation damping) and $P-\theta$ effects is presented in detail.

\subsection{Associated generalized variables}

As usual is the case for a macro-element, the associated generalized variables (displacement and force vectors) are dimensionless $[14,16]$. They are defined hereafter (for any $a, a^{\prime}$ defines the corresponding dimensionless variable): vertical force $V^{\prime}$, horizontal forces $H_{x}^{\prime}, H_{y}^{\prime}$ and moments $M_{x}^{\prime}, M_{y}^{\prime}$, but also the corresponding displacements, vertical settlement $u_{z}^{\prime}$, horizontal displacements $u_{x}^{\prime}$, $u_{y}^{\prime}$ and rotations $\theta_{x}^{\prime}, \theta_{y}^{\prime}$. Torque moment $\left(M_{z}^{\prime}\right)$ is not taken into account (Fig. 1). 


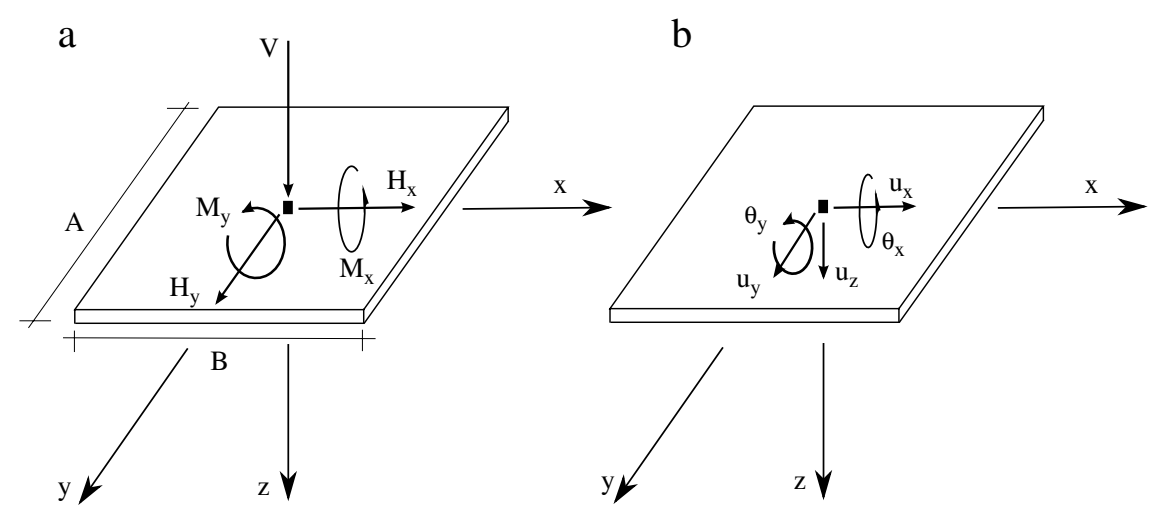

Fig. 1. Generalized variables: (a) forces and (b) displacements for a rectangular foundation.
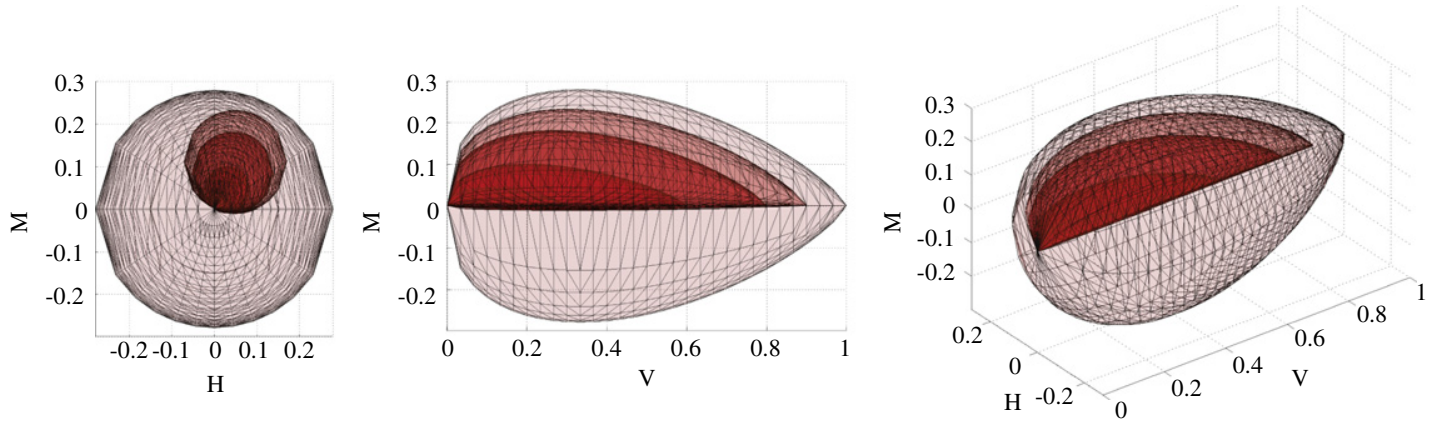

Fig. 2. Loading surfaces and failure criterion in the planes $\left(H_{x}^{\prime}-M_{y}^{\prime}\right),\left(M_{y}^{\prime}-V^{\prime}\right)$ and in the space $\left(H_{x}^{\prime}-M_{y}^{\prime}-V^{\prime}\right)$.

\subsection{Decomposition of the three mechanisms: Elasticity plasticity and uplift}

The SSI macro-element takes into account three different mechanisms: elasticity, plasticity of the soil and uplift of the foundation. The total displacement can thus be decomposed as a sum of an elastic, plastic and uplift part:

$\underline{\mathbf{u}}=\underline{\mathbf{u}^{\mathbf{e l}}}+\underline{\mathbf{u}^{\mathbf{p l}}}+\underline{\mathbf{u}^{\mathbf{u p}}}$.

Uplift is defined as the negative vertical displacement of the center of the foundation. It is the result of rocking, i.e. the fact that the foundation rotates according to $\theta_{x}$ or $\theta_{y}$ (a part of the foundation loses contact with the soil). In order to compute uplift, the simple plasticity of the soil is not sufficient and a new nonlinear mechanism must be introduced in the macro-element. The reason is that the actual plasticity mechanism of the macro-element can take into account only settlements (positive values of the vertical displacement, $u_{z}^{\prime}>0$ ).

Plasticity and uplift are strongly coupled [3]. Both are formulated according to the classical theory of plasticity and their numerical implementation follows the theory of multi-mechanisms.

\subsection{Elastic behavior}

The elastic part of the constitutive law is defined as $\underline{\mathbf{F}}=\underline{\mathbf{K}}^{\mathbf{e l}} \underline{\mathbf{u}}{ }^{\mathbf{e l}}$, where the displacement $\underline{\mathbf{u}^{\mathbf{e l}}}$ and force vectors $\underline{\mathbf{F}}$ are dimensionless. The elastic stiffness matrix $\underline{\mathbf{K}}^{\mathbf{e l}}$ is calculated using the real part of the static impedances. It is considered diagonal, i.e. there is no coupling between the different directions of the loading.

\subsection{Plasticity mechanism}

The failure criterion for the plasticity mechanism is defined for an overturning mechanism with uplift [23]. The adaptation in 3D is presented in [15]. Thanks to the use of dimensionless variables, the problem is solved by adding the two terms related with the horizontal force and moment according to the other axis and assuming axial symmetry. In 3D, the loading surfaces follow the same philosophy and one finally obtains the following 5D surface [15] (Fig. 2):

$$
\begin{aligned}
& f_{c}(\underline{\mathbf{F}}, \underline{\boldsymbol{\tau}}, \rho, \gamma) \equiv\left(\frac{H_{x}^{\prime}}{\rho a V^{\prime c}\left(\gamma-V^{\prime}\right)^{d}}-\frac{\alpha_{1}}{\rho}\right)^{2} \\
& \quad+\left(\frac{M_{y}^{\prime}}{\rho b V^{\prime e}\left(\gamma-V^{\prime}\right)^{f}}-\frac{\alpha_{2}}{\rho}\right)^{2}+\left(\frac{H_{y}^{\prime}}{\rho a V^{\prime c}\left(\gamma-V^{\prime}\right)^{d}}-\frac{\alpha_{3}}{\rho}\right)^{2} \\
& \quad+\left(\frac{M_{x}^{\prime}}{\rho b V^{\prime e}\left(\gamma-V^{\prime}\right)^{f}}-\frac{\alpha_{4}}{\rho}\right)^{2}-1=0 .
\end{aligned}
$$

The coefficients $a, b$ define the size of the surface in the planes $\left(H^{\prime}-M^{\prime}\right) . c, d, e$ and $f$ define the parabolic shape of the surface in the planes $\left(V^{\prime}-M^{\prime}\right)$ and $\left(V^{\prime}-H^{\prime}\right)$. Theses parameters can be fitted using different experimental results on shallow foundations found in the literature $[1,9,10] . \underline{\boldsymbol{\tau}}=\left[\alpha_{1}, \alpha_{2}, \alpha_{3}, \alpha_{4}\right]$ is the kinematics hardening vector composed of 4 kinematics hardening variables and $\rho$ the isotropic hardening variable. The variable $\gamma$ is chosen to parametrize the second intersection point of the loading surface with the $V^{\prime}$ axis (the other point is the origin of the space) and its evolution along the $V^{\prime}$ axis. The evolutions of the hardening variables are obtained considering experimental results and numerical simulations [3] of foundations under cyclic loadings.

The failure criterion is given by Eq. (2) considering $\left(\alpha_{1}, \alpha_{2}, \alpha_{3}\right.$, $\left.\alpha_{4}, \rho, \gamma\right)=(0,0,0,0,1,1)$.

The flow rule used is associated in the $\left(H_{x}^{\prime}, M_{y}^{\prime}, H_{y}^{\prime}, M_{x}^{\prime}\right)$ hyperplane and nonassociated in the $\left(H_{x}^{\prime}, V^{\prime}\right),\left(M_{y}^{\prime}, V^{\prime}\right),\left(H_{y}^{\prime}, V^{\prime}\right)$, $\left(M_{x}^{\prime}, V^{\prime}\right)$ planes. It is presented in details in [14,15]. 


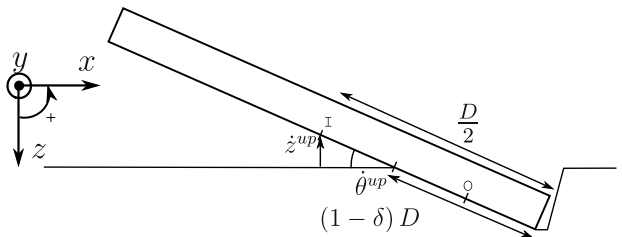

Fig. 3. Kinematics of a foundation for the uplift mechanism.

\subsection{Uplift mechanism}

The mechanism presented hereafter describes in a phenomenological way uplift using a unique state variable $\delta$ as the hardening variable. This variable represents the percentage of the surface of the uplifted footing [3], see Fig. 3 (for any $a, \dot{a}$ defines the derivative with respect to time). We assume that uplift is not influenced by horizontal forces. In the following, the symbols $\oplus$ and $\ominus$ are used to differentiate the directions of the loading $\left(M^{\prime}>0\right.$ or $\left.M^{\prime}<0\right)$.

In the model, the uplift mechanism is described according to the classical plasticity theory. The particularity however is that the loading surface evolves in loading and in unloading (i.e. unloading is not linear elastic, as it is usually the case in a classical plasticity law) with 2 different hardening rules (one in loading and a different one in unloading).

The mathematical expression of the loading surface for the direction $\oplus$ is provided by Eq. (3) (the same relations can be provided for the mechanism $\ominus$ ). Its expression is always positive to make sure it is activated in loading and in unloading (Fig. 4).

$f^{\oplus} \equiv\left|M^{\prime}-\frac{V^{\prime}}{q_{1}}\left(\mathrm{e}^{-A V^{\prime}}+q_{2} \beta^{\oplus}\right)\right|=0$.

With $A=2.5$ a dimensionless parameter of the constitutive law. For a circular foundation we have $q_{1}=6, q_{2}=2$, for a rectangularstrip foundation $q_{1}=4, q_{2}=1$.

The evolution of $\beta^{\oplus}$ (the same is valid for $\ominus$ ) is given by Eq. (4). This variable is a function of the maximum percentage $\delta_{\max }^{\oplus}$ reached during the loading path.

$\beta^{\oplus}=\delta_{\max }^{\oplus}(1-\eta)+\eta \delta^{\oplus}$

$\eta$ is given by Eq. (5)

$\eta=4-3 \mathrm{e}^{-4 V^{\prime}}$.

It is also necessary to introduce the surface defining the elastic limit zone. The loading surfaces being always positive, a test on the elastic surface allows knowing in which mechanism (uplift or elastic) is the model. Its mathematical expression is given in Eq. (6) (Fig. 4):

$f_{\mathbf{e l}}^{\oplus} \equiv M^{\prime}-\frac{V^{\prime}}{q_{1}} q_{2} \delta_{\max }^{\oplus}(1-\eta)-\frac{V^{\prime}}{q_{1}} \mathrm{e}^{-A V^{\prime}}=0$.
From the uplift mechanism, failure occurs when the foundation is completely detached of the soil, i.e. when $\delta^{\oplus}=\beta^{\oplus}=1$.

The flow rule for the uplift mechanism is found through geometric considerations, assuming that the center of rotation of the foundation stays always at the middle of the non-uplifted segment $[15,17]$. The adaptation in 3D of the uplift mechanism consists in coupling the two directions by considering a projection of the moments in the principal base $[15,17]$.

\subsection{Coupling between the plasticity and uplift mechanism}

Coupling of the plasticity and the uplift mechanisms is finally done following the classical theory of the multi-mechanisms, Fig. 5, [24]. A representation of the failure criteria for both the plasticity and the uplift mechanisms are given in Fig. 5.

The coupling between the two plastic mechanisms (i.e. plasticity and uplift) consists in writing the total plastic displacement (or velocity) as the contribution of the plastic displacement (or velocity) of each mechanism Eq. (7). For this, two plastic multipliers $\left(\dot{\lambda}^{m}\right)$ are introduced associated with the mechanisms.

$\underline{\dot{\mathbf{u}}^{\mathbf{p l}}}=\sum_{m=1}^{2} \underline{\dot{\mathbf{u}}}^{\mathbf{p l}^{m}}=\sum_{m=1}^{2} \dot{\lambda}^{m} \frac{\partial g^{m}}{\partial \underline{\mathbf{F}}}$

For nonlinear hardening mechanisms, the resolution of such a problem is done writing the two loading surfaces $\left(f^{1}\right.$ and $f^{2}$ ) using a first order Taylor development at the converged current point. This development gives two linear equations depending on the increment of the two plastic multipliers $\delta(\Delta \lambda)^{1}$ and $\delta(\Delta \lambda)^{2}$. The resolution of the two coupled linear equations provides the increments of the plastic multipliers. The force, the plastic displacements and the hardening variables for each mechanism are then calculated (see [24]).

The principal difficulty in treating this problem is to evaluate the number $(0,1$ or 2$)$ of activated mechanisms. A numerical test on each mechanism is therefore needed at each step.

\section{Considering radiation damping}

For dynamic SSI problems, one has to take into account damping due to radiation dissipation of energy in a semi-infinite medium. We deal with this problem using the classical visco-plasticity theory and particularly the description given in [25]. From a rheological point of view, the solution consists in adding a damper parallel to the two nonlinear mechanisms represented in Fig. 6 .

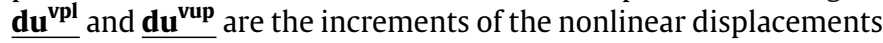
coming from plasticity and uplift respectively (the superscript $\mathbf{v}$ symbolizes the viscous component of the mechanism).

In a finite element code, displacements are imposed on the macro-element that has to return the associated forces. Fig. 7
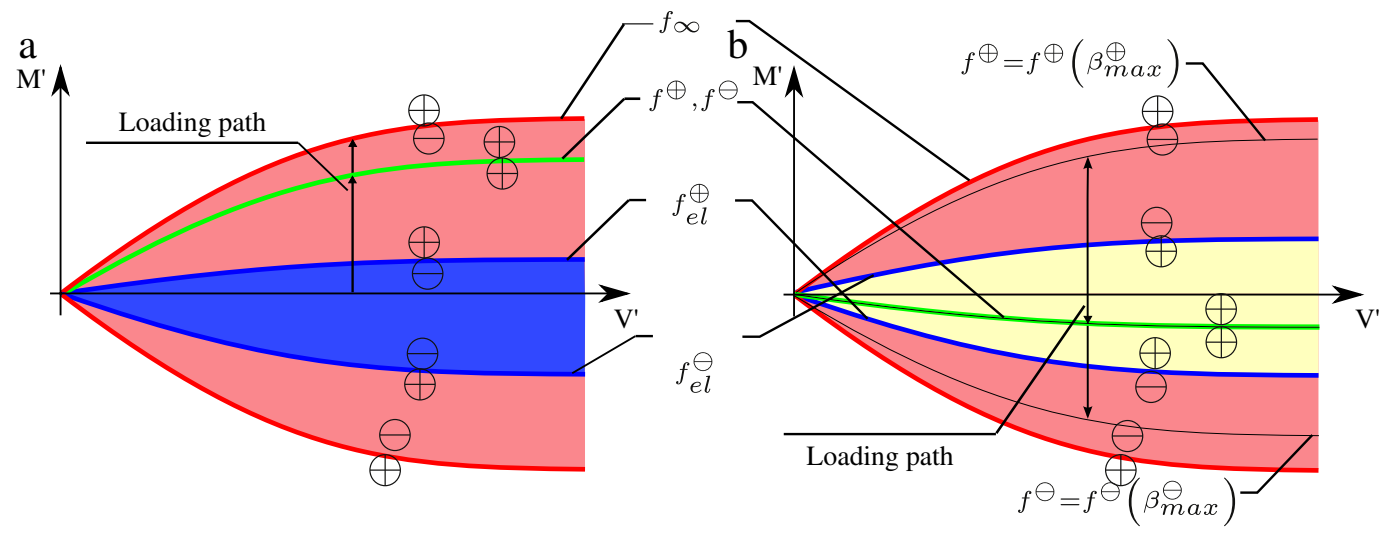

Fig. 4. Loading surfaces, failure criterion and elastic limits with their signs. 

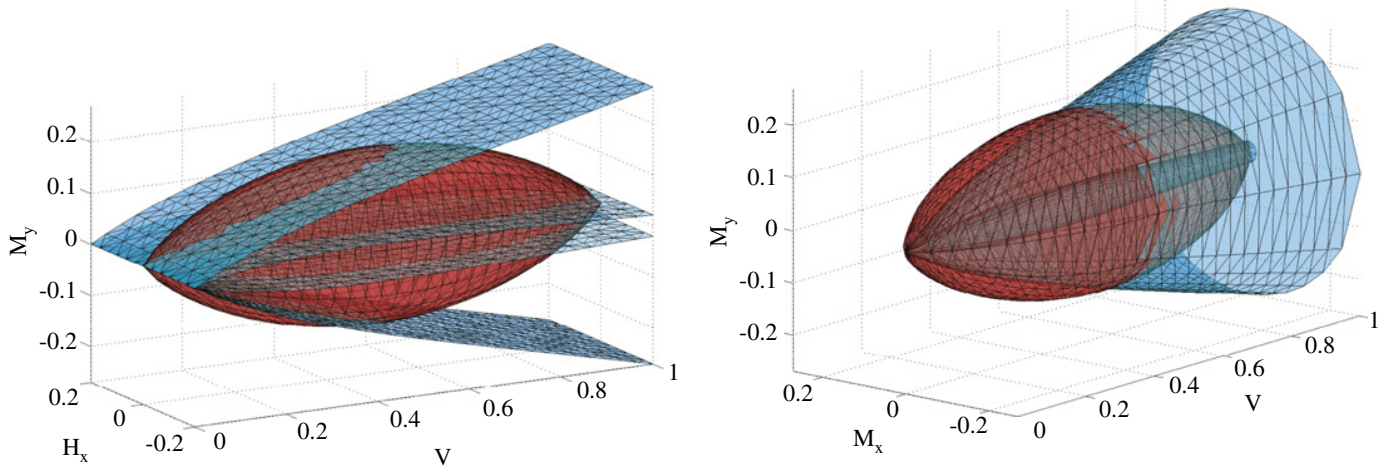

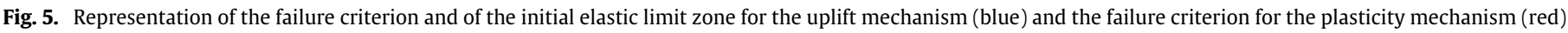
in the spaces $M_{y}, H_{x}, V$ et $M_{y}, M_{x}, V$. (For interpretation of the references to colour in this figure legend, the reader is referred to the web version of this article.)

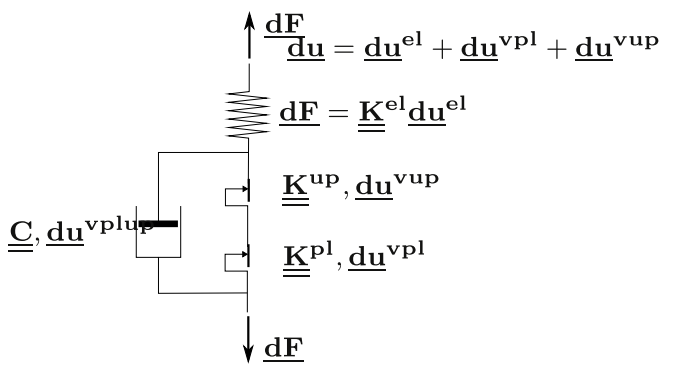

Fig. 6. Rheological model of the macro-element considering radiation damping.

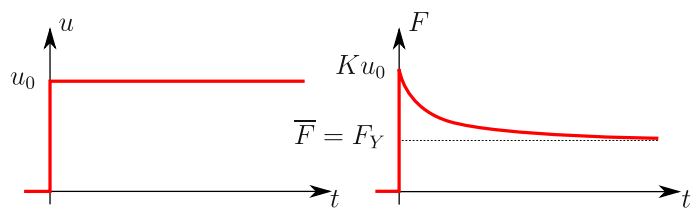

Fig. 7. Constant displacement increment and associate forces for the 1D rheological model.

represents this behavior for a $1 \mathrm{D}$ problem and for a given instantaneous displacement increment $\underline{\mathbf{d u}}=u_{0}$ at $t=0$. After $t=0$ the displacement increment stays constant (does not change with time).

We can distinguish two cases according to the value of the displacement increment:

- the imposed displacement generates a force smaller than the plastic limit (the loading point stays into the elastic domain). The damper is not loaded and all displacements are retrieved by the elastic spring. The instantaneous response at $t=0$ does not evolve with time.

- the imposed displacement generates a force bigger than the plastic limit. The instantaneous response at $t=0$ is denoted $\underline{\mathbf{F}}=K u_{0}$. Then, while the imposed displacement stays constant, the viscous displacements $\mathbf{d u}^{\mathbf{v p l}}$ and $\mathbf{d} \mathbf{u}^{\mathbf{v u p}}$ increase with time and so the force in the elastic spring decreases exponentially (like in a relaxation test). If the time step is very long, the force tends to the asymptotic response $F_{Y}$.

For this second case, the differential equation governing the evolution of the visco-plastic displacement $u^{\mathbf{v p l}}$ takes the following form (with $\eta_{v}$ the viscous parameter):

$\dot{u}^{\mathbf{v p l}}=\frac{1}{K \eta_{v}}\left[F(t)-F_{Y}\right]$.

The solution of this equation provides the force as function of time:

$F(t)=\left[K u_{0}-F_{Y}\right] \mathrm{e}^{\frac{-K t}{\eta_{v}}}+F_{Y}$.
Solution of the problem is thus known whatever the time $t$, if one knows the viscous parameter $\eta_{v}$, the instantaneous elastic solution $K u_{0}$ and the permanent solution $F_{Y}$. This permanent solution corresponds to the solution of the system without the damper.

For the 3D problem, [25] suggests a similar expression for the differential equation:

$\underline{\dot{\mathbf{u}}^{\text {vplup }}}=\frac{{\underline{\underline{\mathbf{K}^{\mathbf{l}}}}}^{-1}}{\eta_{v}}[\underline{\mathbf{F}}(t)-\underline{\mathbf{F}}]$.

Again, solving the 3D problem consists in evaluating the instantaneous plastic and uplift displacements and the hardening variables at the end of the time step using the model without damper (permanent solution).

The viscous parameter $\eta_{v}$ is calculated thanks to the dynamic impedances given in [26] (only the vertical component of the impedance - the predominant component - is considered):

$\eta_{v}=\frac{C_{z z}}{K_{z z}^{\mathbf{e l}}}$

For a shallow foundation we have:

$C_{z z}=\rho V_{S_{0}} \frac{3.4}{\pi(1-v)} S$

where $\rho$ the density of the soil, $v$ its Poisson ratio, $V_{S_{0}}$ the velocity of the shear waves in the soil and $S$ the area of the foundation.

All the components of the radiation damping matrix are calculated using $\eta_{v}$, leading to proportional terms between the damping matrix and the stiffness matrix.

$\underline{\underline{\mathbf{C}}}=\eta_{v} \underline{\underline{\mathbf{K}}}^{\mathrm{el}}$.

The components of the radiation damping matrix are finally added to the terms of the global damping matrix coming from the Rayleigh damping on the structural level.

Note: From a conceptual point of view, this rheological model does not describe correctly radiation damping that is situated in the far and not in the close field. In other words, the damper should have been placed in parallel with the linear spring. Nevertheless, the chosen description helps avoiding numerical problems for the case of instantaneous displacement increments. It also allows taking into account easily energy dissipation.

\section{Considering $P-\theta$ effects}

Let's denote $V^{\prime}$ the "normal" force (written in the local coordinate system, always perpendicular to the foundation) and $V_{Z}^{\prime}$ the "vertical" force (in the global coordinate system, i.e generally the weight of the structure), see Fig. 8. 


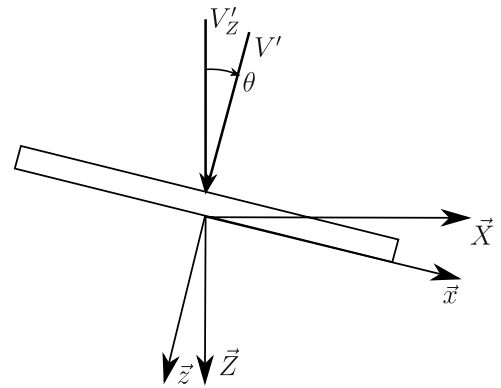

Fig. 8. Influence of the $P-\theta$ effect on the normal force stabilizing the foundation.
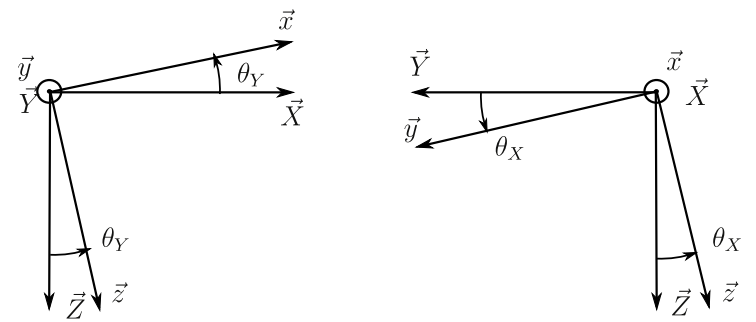

Fig. 9. $P-\theta$ effect, two coordinate system modifications to be considered in the case of moderate rotations.

- When considering small rotations, $V^{\prime}$ and $V_{Z}^{\prime}$ are almost identical and constant (provided that the vertical mode is not excited and the vertical force does not change while the foundation rotates).

- For moderate rotations, the normal force $V^{\prime}$ can decrease significantly compared to the vertical force $V_{Z}^{\prime}$ that remains constant $(P-\theta$ effect). This decrease generates a decrease in the values of moments or forces leading to failure, as one can see from the forms of the failure criteria (Fig. 5). The foundation is thus found destabilized. This phenomenon is translated in fluctuating plateaus in the force-displacement curve.

In order to take into account this phenomenon, one has to ensure that at every step of the calculation the normal force in the macro-element equals the projection of the vertical force. The way to do this is explained hereafter:

The reduced force array written in the fixed global coordinate system $(\vec{X}, \vec{Y}, \vec{Z})$ has the following form (with exponent ${ }^{\mathrm{t}}$ for the transpose):

${ }^{\mathbf{t}} \underline{\mathbf{F}}_{\mathbf{g}}=\left[V_{Z}^{\prime}, H_{X}^{\prime}, M_{Y}^{\prime}, H_{Y}^{\prime}, M_{X}^{\prime}\right]$.

The reduced force array written in the rotating local coordinate system of the foundation $(\vec{x}, \vec{y}, \vec{z})$ becomes:

${ }^{\mathbf{t}} \underline{\mathbf{F}}=\left[V^{\prime}, H_{x}^{\prime}, M_{y}^{\prime}, H_{y}^{\prime}, M_{x}^{\prime}\right]$.

For a 3D problem, two successive and independent modifications (rotations) of the coordinate system can be considered. The first is a $\theta_{Y}$ angle rotation (according to the $\vec{Y}$ axis), represented by the linear application $M\left(r o t, \theta_{Y}\right)$. The second is a $\theta_{X}$ angle rotation (according to the $\vec{x}$ axis) represented by the linear application $M\left(\right.$ rot,$\left.\theta_{x}\right)$.

The assumption of moderate rotations allows considering that after the $\theta_{Y}$ rotation, the $\vec{x}$ axis almost coincides with the $\vec{X}$ axis and thus the $\theta_{x}$ angle is almost equal to $\theta_{X}$ angle (Fig. 9). Thus, this assumption leads to $M\left(\operatorname{rot}, \theta_{X}\right) \approx M\left(\operatorname{rot}, \theta_{X}\right)$. Of course, a small error is introduced in calculating the force to the local coordinate system. Nevertheless, this assumption permits to simplify the problem because the angles $\theta_{X}$ and $\theta_{Y}$ provided by the finite element code can be directly used. Moreover, this assumption allows obtaining that both operators $M\left(\operatorname{rot}, \theta_{Y}\right)$ and $M\left(\right.$ rot,$\left.\theta_{X}\right)$ are commutative.
Table 1

Camus IV: Parameters of the lumped masses.

\begin{tabular}{lll}
\hline Height $(\mathrm{m})$ & Masses $(\mathrm{kg})$ & Inertia $\left(\mathrm{kg} \cdot \mathrm{m}^{2}\right)$ \\
\hline$h_{1}=0.1$ & $M_{1}=4786$ & $J_{1}=1600$ \\
$h_{2}=1.4$ & $M_{2}=6825$ & $J_{2}=3203$ \\
$h_{3}=2.3$ & $M_{3}=6825$ & $J_{3}=3203$ \\
$h_{4}=3.2$ & $M_{4}=6825$ & $J_{4}=3203$ \\
$h_{5}=4.1$ & $M_{5}=6825$ & $J_{5}=3203$ \\
$h_{6}=5$ & $M_{6}=6388$ & $J_{6}=3124$ \\
\hline
\end{tabular}

For moderate rotations, the relationship linking the vector written in the global coordinate system with the vector in the local one is finally provided by:

$$
\begin{aligned}
{\left[\begin{array}{l}
V^{\prime} \\
H_{X}^{\prime} \\
M_{y}^{\prime} \\
H_{y}^{\prime} \\
M_{x}^{\prime}
\end{array}\right]=} & \underbrace{\left[\begin{array}{ccccc}
\cos \theta_{Y} & \sin \theta_{Y} & 0 & 0 & 0 \\
-\sin \theta_{Y} & \sin \theta_{Y} & 0 & 0 & 0 \\
0 & 0 & 1 & 0 & 0 \\
0 & 0 & 0 & 1 & 0 \\
0 & 0 & 0 & 0 & \cos \theta_{Y}
\end{array}\right]}_{M\left(\text { rot, } \theta_{Y}\right)} \\
\times & \underbrace{\left[\begin{array}{ccccc}
\cos \theta_{X} & 0 & 0 & -\sin \theta_{X} & 0 \\
0 & 1 & 0 & 0 & 0 \\
0 & 0 & \cos \theta_{X} & 0 & 0 \\
\sin \theta_{X} & 0 & 0 & \cos \theta_{X} & 0 \\
0 & 0 & 0 & 0 & 1
\end{array}\right]}_{M\left(r o t, \theta_{X}\right)}\left[\begin{array}{c}
V_{Z}^{\prime} \\
H_{X}^{\prime} \\
M_{Y}^{\prime} \\
H_{Y}^{\prime} \\
M_{X}^{\prime}
\end{array}\right] .
\end{aligned}
$$

\section{Numerical simulation of the CAMUS IV structure}

The simulation of the CAMUS IV experiment [19-21], performed on the seismic table of CEA Saclay, is presented hereafter in order to evaluate the efficiency of the macro-element to predict the behavior of a slender structure submitted to dynamic loading. CAMUS IV is an experiment in the line of a series carried out within the framework of the European research projects ICONS-TMR, ECOEST PREC8, SAFERR. The test specimen represents a fifth-story building on a $1 / 3$ scale made of 2 reinforced concrete walls and two rectangular foundations (Fig. 10). The structure rests on a sand box. The dimensions of the foundations and of the sand box are given on Fig. 10(b). The total mass of the test specimen is about $38500 \mathrm{~kg}$.

Lumped masses are considered at each floor, taking into account the mass of the corresponding slab and the upper and lower part of the wall (Table 1 and Fig. 10(c)). Fig. 10(c) gives also a representation of the finite element discretization. The walls are decomposed into five linear elastic Bernoulli beam elements. The reason for this choice is that during the tests the behavior of the structure was linear elastic, the nonlinearities being concentrated in the soil and between the soil and the foundation. A 2\% Rayleigh damping is also added (on the 1st and fourth modes) to take into account the damping in the structure.

Soil conditions and particularly the thickness of the sandbox do not match with the domain of validity of the macro-element (semi-infinite). That is why the stiffness of the soil and the parameters of the macro-element are fitted from the experimental results: the initial stiffnesses are evaluated according to the forces-displacements relationships and the parameters of the failure criterion according to their plateaus. They are presented in Table 2.

\subsection{Modal analysis}

The numerical model, without further calibration, provides the natural frequencies presented in Table 3. The first mode (lateral) has a low frequency of $3.5 \mathrm{~Hz}$ and it is found equal to the experimental one. The second mode (compression-extension, vertical mode) is found stiffer than the experimental one. 

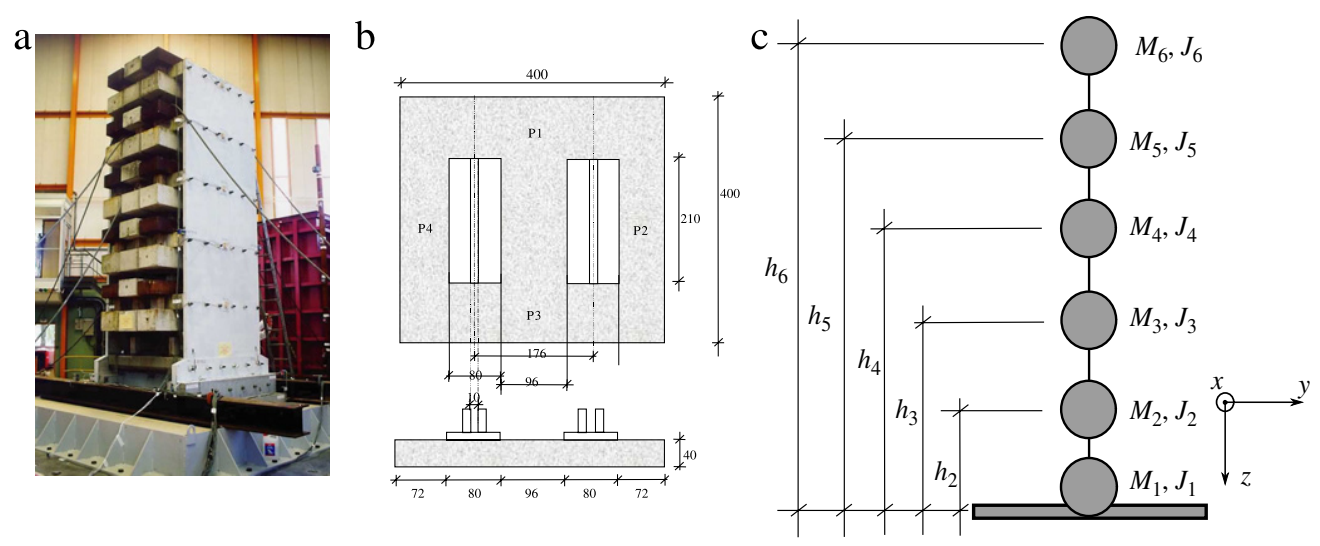

Fig. 10. Camus IV: (a) Photo, (b) foundation scheme and (c) lumped masses.
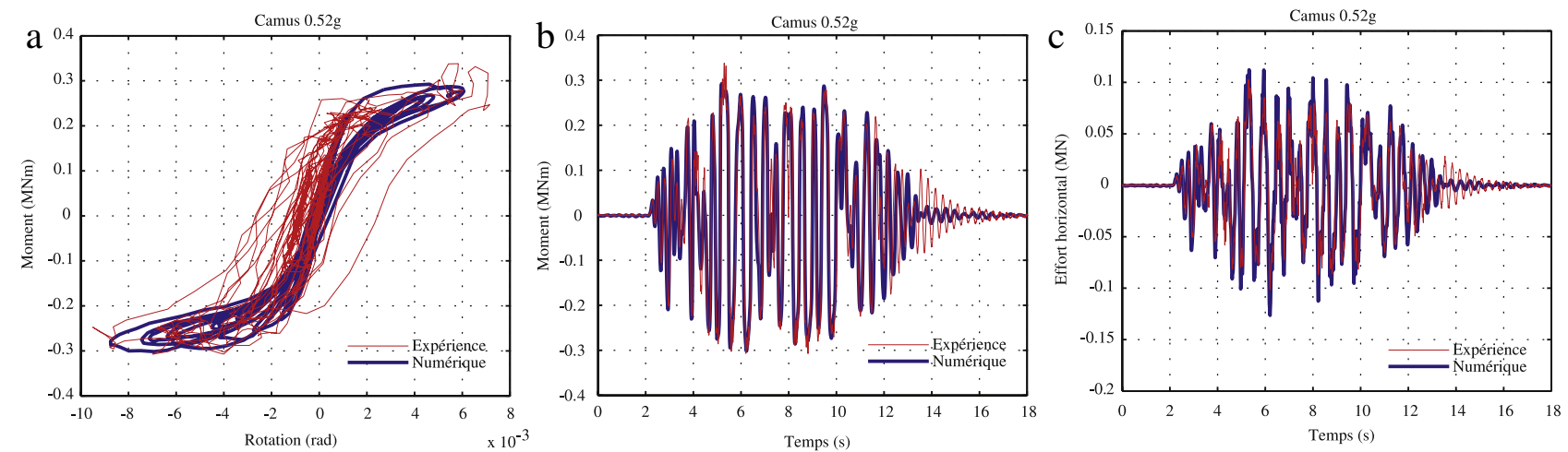

Fig. 11. Camus IV: Moment-rotation, rotation-time and horizontal force-time relationships for the test Nice $0.52 \mathrm{~g}$.

Table 2

Camus IV: Parameters of the macro-element.

\begin{tabular}{llll}
\hline Plastic model & \multicolumn{3}{l}{ Stiffness } \\
\hline$(a, b, c, d, e, f)$ & $(1,1,1,1,1)$ & $K_{\theta \theta}^{\mathrm{el}}$ & $280 \mathrm{MN} \mathrm{m} / \mathrm{rad}$ \\
$q_{\max }$ & $0.35 \mathrm{MPa}$ & $K_{h h}^{\mathrm{el}}$ & $70 \mathrm{MN} / \mathrm{m}$ \\
& & $K_{z z}^{\mathrm{el}}$ & $200 \mathrm{MN} / \mathrm{m}$ \\
\hline Uplift model & & Radiation damping \\
\hline$q_{1}$ & 4 & $C_{\theta \theta}$ & $0.28 \mathrm{MNm} \mathrm{s} / \mathrm{rad}$ \\
$q_{2}$ & 1 & $C_{h h}$ & $0.07 \mathrm{MN} \mathrm{s} / \mathrm{m}$ \\
& & $C_{z z}$ & $0.2 \mathrm{MN} \mathrm{s} / \mathrm{m}$ \\
\hline
\end{tabular}

Table 3

Camus IV: Experimental and numerical natural frequencies.

\begin{tabular}{lcc}
\hline Mode & Frequency $(\mathrm{Hz})$ & \\
\cline { 2 - 3 } & Test & Numerical \\
\hline 1 (lateral) & 3.5 & 3.5 \\
2 (vertical) & 13 & 14.8 \\
\hline
\end{tabular}

\subsection{Experimental vs. numerical results}

Several input motions have been used during the experiments with increasing maximum acceleration till $0.52 \mathrm{~g}$. The signal comes from the synthetic Nice earthquake which corresponds to the design spectra of the French rules PS92. Accelerations are applied along the directions of the walls. Comparisons between experimental and numerical results are given in Figs. 11 and 12.

Forces and displacements are in phase with the experimental results and the peaks are correctly reproduced. Vertical settlements are found larger than in the experiment. The reason is that during the experiments, the sand box had been subjected to three successive tests that led to certain compaction of the sand in each test (not taken into account by the model). Numerically, the motions have been applied independently, as if the sand box did not undergo any prior loading.

\section{Numerical simulation of a seven-story RC building}

\subsection{Presentation of the structure}

A full-scale vertical slice of a seven-story reinforced concrete (RC) walls building (Fig. 13) has been subjected to increasing intensity of uniaxial earthquake ground motions on the new NEES Large High-Performance Outdoor Shake Table (international benchmark NEES/UCSD performed between October 2005 and January 2006 [22]). The structure is composed of 2 main perpendicular walls: the web wall and the flange wall linked with the slabs. It is fixed to the shaking table. The building slice was designed using a displacement-based and capacity approach for a site at Los Angeles resulting in design lateral forces that are significantly smaller than those currently specified in building codes used in the United States.

Only the direction Y of loading is considered (parallel to the web wall, see Fig. 13). Four input motions at different intensities have been used coming from the Sylmar Medical Facility free-field record obtained during the 1994 Northridge Earthquake (EQ1 to EQ4). At the end of the experimental program significant damage (crushing of concrete and buckling of steel bars) was concentrated at the base of the web wall.

The numerical simulations presented hereafter are divided in two sections:

- In Section 6.2 we demonstrate briefly the capacity of the numerical strategy to reproduce the nonlinear behavior of the structure considered fixed at the base. Actually, this work constitutes our answer to the international benchmark NEES/UCSD and the 

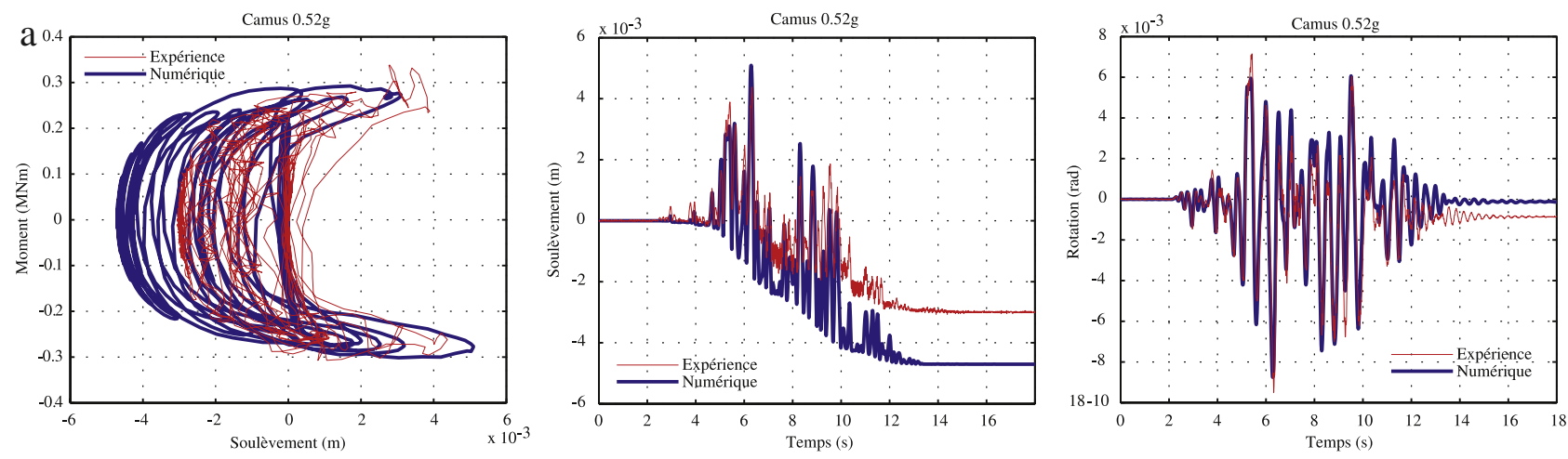

Fig. 12. Camus IV: Moment-vertical displacement, vertical displacement-time and rotation-time relationships for the test Nice $0.52 \mathrm{~g}$.
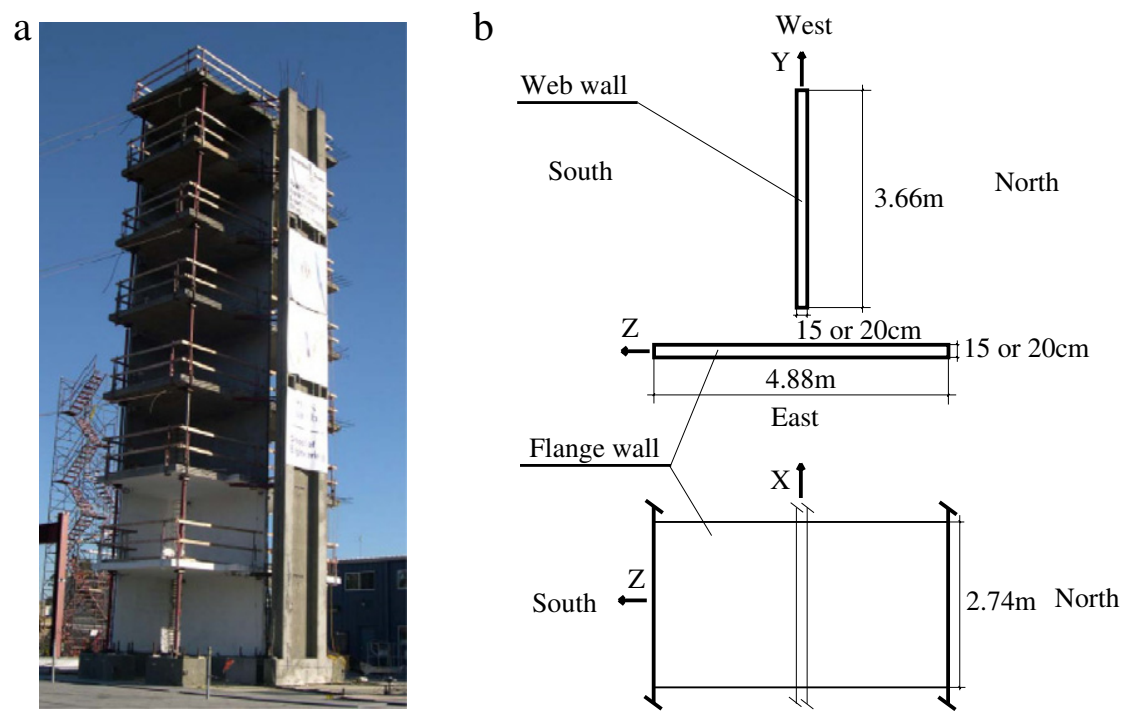

Fig. 13. NEES building: (a) North West view of the test specimen and (b) Geometric data of the test specimen, [22].

comparisons with the experimental response are "blind" (no prior knowledge of the test results). The building is modeled using Timoshenko multifiber beam elements $[27,28]$. Constitutive material laws are based on damage mechanics for concrete [29] and plasticity for steel [30,31]. The Timoshenko multifiber beam element and the damage mechanic law have been introduced into FEDEASLab [18] by the 3S-R group. For more details concerning the mesh, the material parameters and the response of the numerical model compared with the experimental results the reader is invited to look in [32].

- In Section 6.3 we introduce the macro-element at the base of the numerical mesh used previously. In other words, the structure is now supposed to have a rigid shallow rectangular foundation lying on a soil of given parameters. By changing the parameters of the macro-element we are able to simulate 5 different soils and their influence into the nonlinear behavior of the RC building. Comparisons with the behavior of the fixed base building are also presented.

\subsection{Numerical model of the structure considered fixed to the shaking table}

Fig. 14(a) gives a representation of the finite element discretization. The web wall and the flange wall are decomposed into 19 multifiber Timoshenko beam elements ( 4 elements for levels 1 and 2, 3 elements for level 3 and 2 elements for levels 5, 6 and 7). The slotted connections between the web wall and the flange wall are simulated using linear bar elements. 4 linear Bernoulli beam elements are used to reproduce the shaking table. Lumped masses
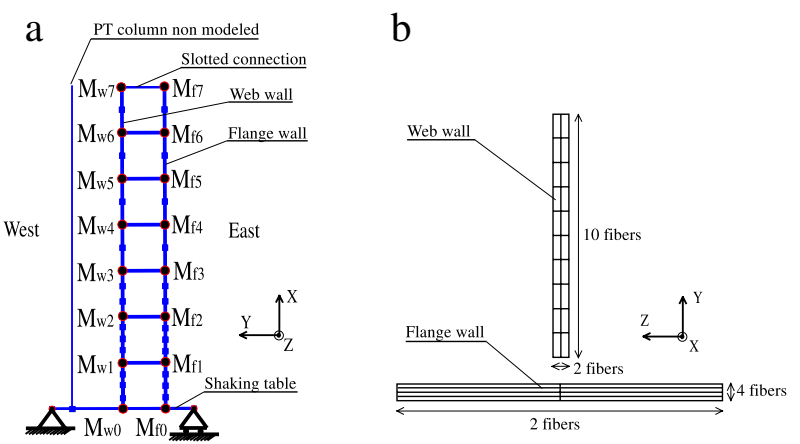

Fig. 14. NEES building (fixed base numerical model): (a) Finite element mesh and lumped masses and (b) fibers in a given section.

are considered at each floor taking into account the mass of the corresponding slab and the upper and lower part of the wall.

The multifiber elements composing the web wall are divided into 20 concrete fibers whereas those of the flange wall are divided into 8 concrete fibers (Fig. 14(b)). The number and the position of the fibers representing the longitudinal reinforcement bars are the same with those in the real section (see details of the sections in the contest rules [22]).

Constitutive model for concrete under cyclic loading ought to take into account some observed phenomena such as decrease in material stiffness due to cracking, stiffness recovery which occurs 

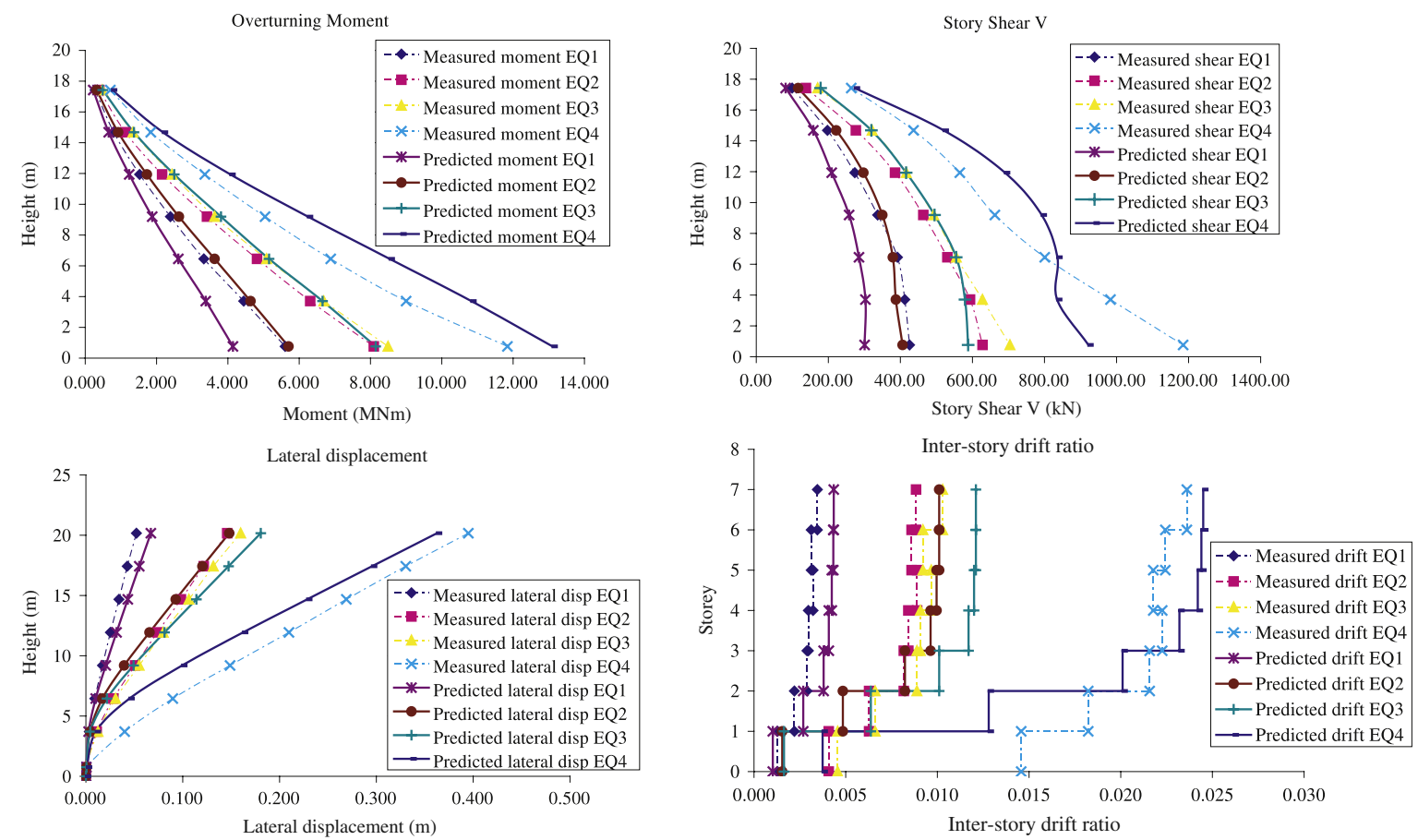

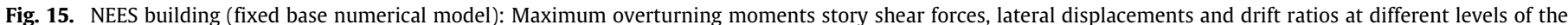
structure for the 4 sequences, comparisons between experimental (dotted lines) and "blind" prediction numerical results (continuous lines).

Table 4

NEES building (SSI numerical model): Characteristics of the soils.

\begin{tabular}{|c|c|c|c|c|}
\hline Number & $\begin{array}{l}\text { Shear velocity } V_{s} \\
\text { Shear modulus } G_{0}\end{array}$ & $\begin{array}{l}\text { Cohesion } c \\
\text { friction angle } \phi\end{array}$ & Stiffness and damping [26] & Ultimate bearing stress $q_{\max }$ \\
\hline $\begin{array}{l}\text { Soil } 1 \\
\text { (S1 class) }\end{array}$ & $\begin{array}{l}V_{s}=70 \mathrm{~m} / \mathrm{s} \\
G_{0}=9.31 \mathrm{MPa}\end{array}$ & $\begin{array}{l}c_{u}=35 \mathrm{kPa} \\
\phi_{u}=0\end{array}$ & $\begin{array}{l}K_{\theta \theta}=295.19 \mathrm{MN} \mathrm{m} / \mathrm{rad} \\
K_{z z}=101.22 \mathrm{MN} / \mathrm{m} \\
K_{h h}=82.35 \mathrm{MN} / \mathrm{m} \\
C_{\theta \theta}=7.49 \mathrm{MNm} \mathrm{s} / \mathrm{rad} \\
C_{z z}=2.57 \mathrm{MN} \mathrm{s} / \mathrm{m} \\
C_{h h}=2.09 \mathrm{MN} \mathrm{s} / \mathrm{m}\end{array}$ & $q_{\max }=0.20 \mathrm{MPa}$ \\
\hline $\begin{array}{l}\text { Soil } 2 \\
\text { (D class) }\end{array}$ & $\begin{array}{l}V_{s}=100 \mathrm{~m} / \mathrm{s} \\
G_{0}=19 \mathrm{MPa}\end{array}$ & $\begin{array}{l}c_{u}=70 \mathrm{kPa} \\
\phi_{u}=0\end{array}$ & $\begin{array}{l}K_{\theta \theta}=601.5 \mathrm{MN} \mathrm{m} / \mathrm{rad} \\
K_{z z}=206.18 \mathrm{MN} / \mathrm{m} \\
K_{h h}=167.8 \mathrm{MN} / \mathrm{m} \\
C_{\theta \theta}=10.70 \mathrm{MNm} \mathrm{s} / \mathrm{rad} \\
C_{z z}=3.67 \mathrm{MN} \mathrm{s} / \mathrm{m} \\
C_{h h}=2.98 \mathrm{MN} \mathrm{s} / \mathrm{m}\end{array}$ & $q_{\max }=0.40 \mathrm{MPa}$ \\
\hline $\begin{array}{l}\text { Soil } 3 \\
\text { (C class) }\end{array}$ & $\begin{array}{l}V_{s}=180 \mathrm{~m} / \mathrm{s} \\
G_{0}=61.5 \mathrm{MPa}\end{array}$ & $\begin{array}{l}c_{u}=250 \mathrm{kPa} \\
\phi_{u}=0\end{array}$ & $\begin{array}{l}K_{\theta \theta}=1951.4 \mathrm{MN} \mathrm{m} / \mathrm{rad} \\
K_{z z}=668.9 \mathrm{MN} / \mathrm{m} \\
K_{h h}=544.4 \mathrm{MN} / \mathrm{m} \\
C_{\theta \theta}=19.50 \mathrm{MNm} \mathrm{s} / \mathrm{rad} \\
C_{z z}=6.60 \mathrm{MN} \mathrm{s} / \mathrm{m} \\
C_{h h}=5.40 \mathrm{MN} \mathrm{s} / \mathrm{m}\end{array}$ & $q_{\max }=1.43 \mathrm{MPa}$ \\
\hline $\begin{array}{l}\text { Soil } 4 \\
\text { (B class) }\end{array}$ & $\begin{array}{l}V_{s}=360 \mathrm{~m} / \mathrm{s} \\
G_{0}=246.2 \mathrm{MPa}\end{array}$ & $\begin{array}{l}c=115 \mathrm{kPa} \\
\phi=30\end{array}$ & $\begin{array}{l}K_{\theta \theta}=7805.1 \mathrm{MN} \mathrm{m} / \mathrm{rad} \\
K_{z z}=2675.6 \mathrm{MN} / \mathrm{m} \\
K_{h h}=2177.7 \mathrm{MN} / \mathrm{m} \\
C_{\theta \theta}=38.24 \mathrm{MNm} \mathrm{s} / \mathrm{rad} \\
C_{z z}=13.20 \mathrm{MN} \mathrm{s} / \mathrm{m} \\
C_{h h}=10.67 \mathrm{MN} \mathrm{s} / \mathrm{m}\end{array}$ & $q_{\max }=4.013 \mathrm{MPa}$ \\
\hline $\begin{array}{l}\text { Sol } 5 \\
\text { (A class) }\end{array}$ & $V_{s}>800 \mathrm{~m} / \mathrm{s}$ & & $\begin{array}{l}K_{\theta \theta}=18302 \mathrm{MN} \mathrm{m} / \mathrm{rad} \\
K_{z z}=\text { infinity } \\
K_{h h}=\text { infinity } \\
C_{\theta \theta}=0 \mathrm{MNm} \mathrm{s} / \mathrm{rad} \\
C_{z z}=0 \mathrm{MN} \mathrm{s} / \mathrm{m} \\
C_{h h}=0 \mathrm{MN} \mathrm{s} / \mathrm{m}\end{array}$ & $q_{\max }=$ infinity \\
\hline
\end{tabular}

at crack closure and inelastic strains concomitant to damage. To simulate this behavior we use a uniaxial damage model with two scalars variables, one in compression and one in tension [29] (shear is considered linear). Inelastic strains are taken into account thanks to an isotropic tensor. A modified version of the classical
Menegoto-Pinto model [30,31] with an isotropic hardening is used for steel.

The calculated response presented in Fig. 15 is close to the experimental behavior, particularly the maximum lateral displacements, shear forces, moments and inter-story drift ratios for the 


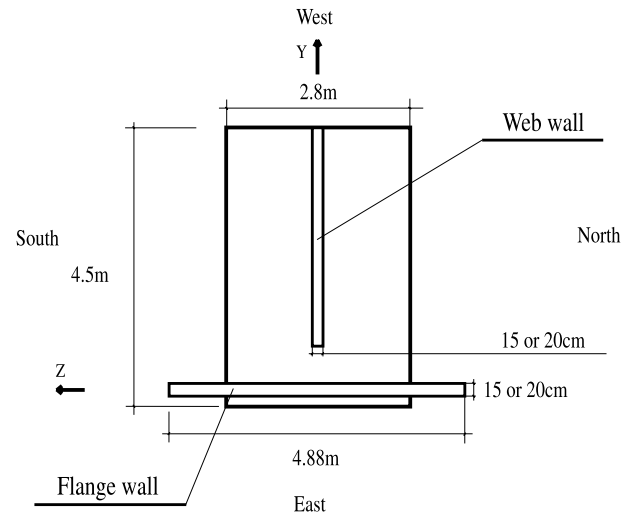

Fig. 16. NEES building (SSI numerical model): Geometric characteristics of the foundation.

four sequences. The internal forces presented here are calculated at the base of the different levels of the building for the 4 sequences (EQ1, EQ2, EQ3 and EQ4).
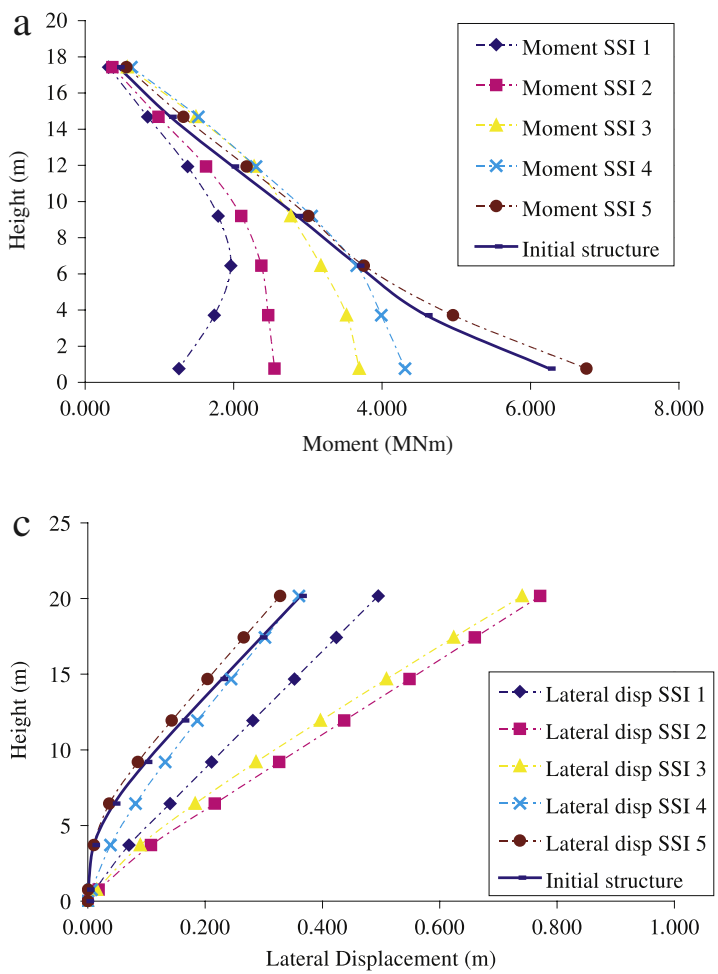

\subsection{Numerical simulations of the structure considering Soil-Structure Interaction}

In this section the numerical mesh of the structure is the same as in Section 6.2, with the only difference that the structure is now supported on the macro-element (the shaking table is not simulated). The structure is supposed to have a rigid shallow rectangular foundation lying on a soil. The geometric characteristics of the footing are given in Fig. 16. The center of the foundation is located below the gravity center of the structure (at $2 \mathrm{~m}$ from the edge of the flange wall).

Various types of soils are considered. Their characteristics are defined in Table 4. All soils have a density $\rho=1900 \mathrm{~kg} \mathrm{~m}^{-3}$ and a Poisson coefficient $v=0.4$. The classification used in this table is taken from [33,34]. The criterion for the classification is the shear wave velocity in the soil (from class A: solid bed rock to class S1: soil with very low characteristics). The elastic stiffness is calculated thanks to the dynamic impedances given in [35].

We present hereafter, and this for the last loading sequence EQ4, the numerical results of the seven-story structure considering the 5 different types of soils:
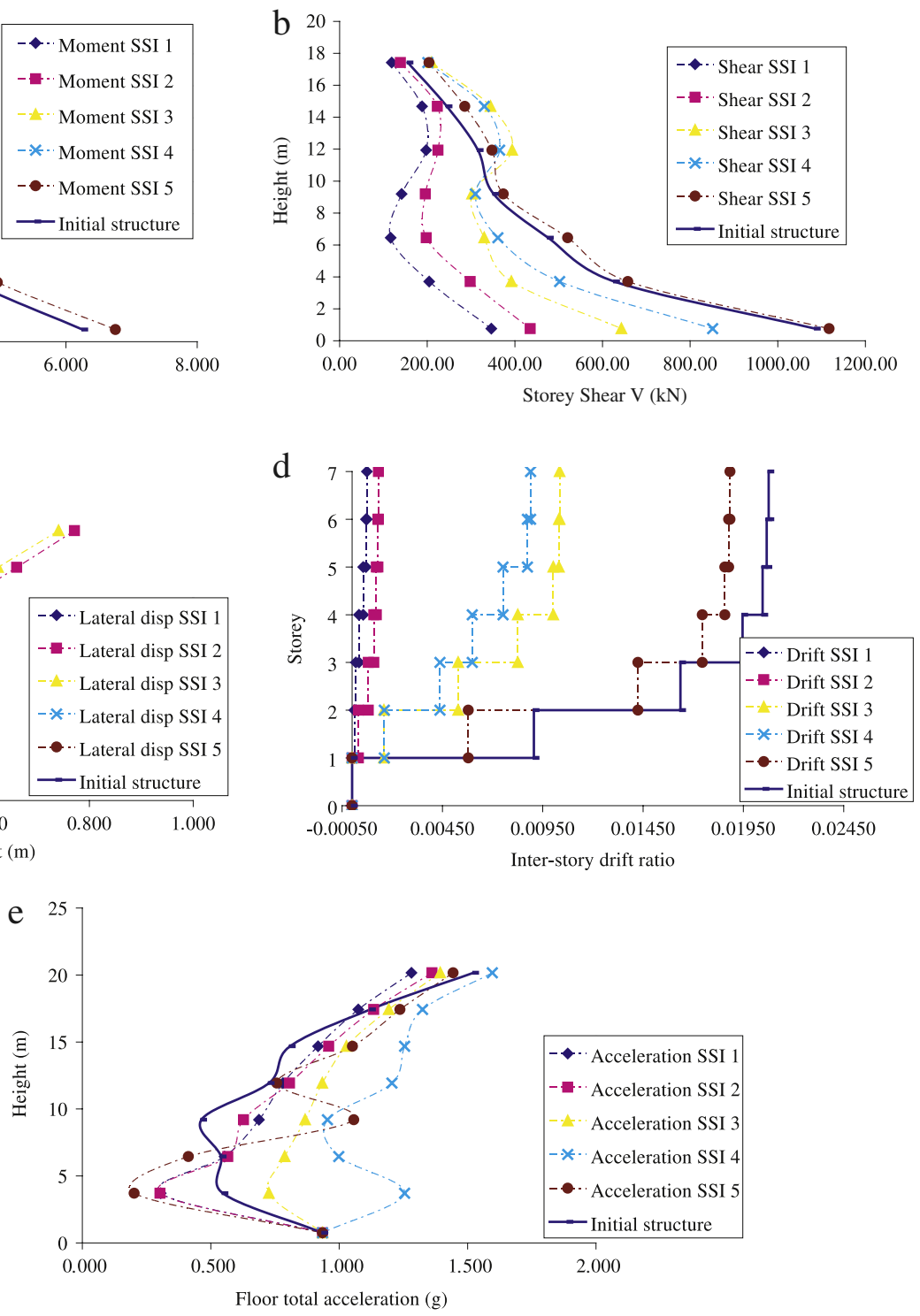

Fig. 17. NEES building (SSI numerical model): (a) Maximum overturning moments, (b) story shears, (c) lateral displacements, (d) drifts and (e) floor accelerations for 5 different soils at the web wall and comparison with the structure fixed to the shaking table (EQ4). 

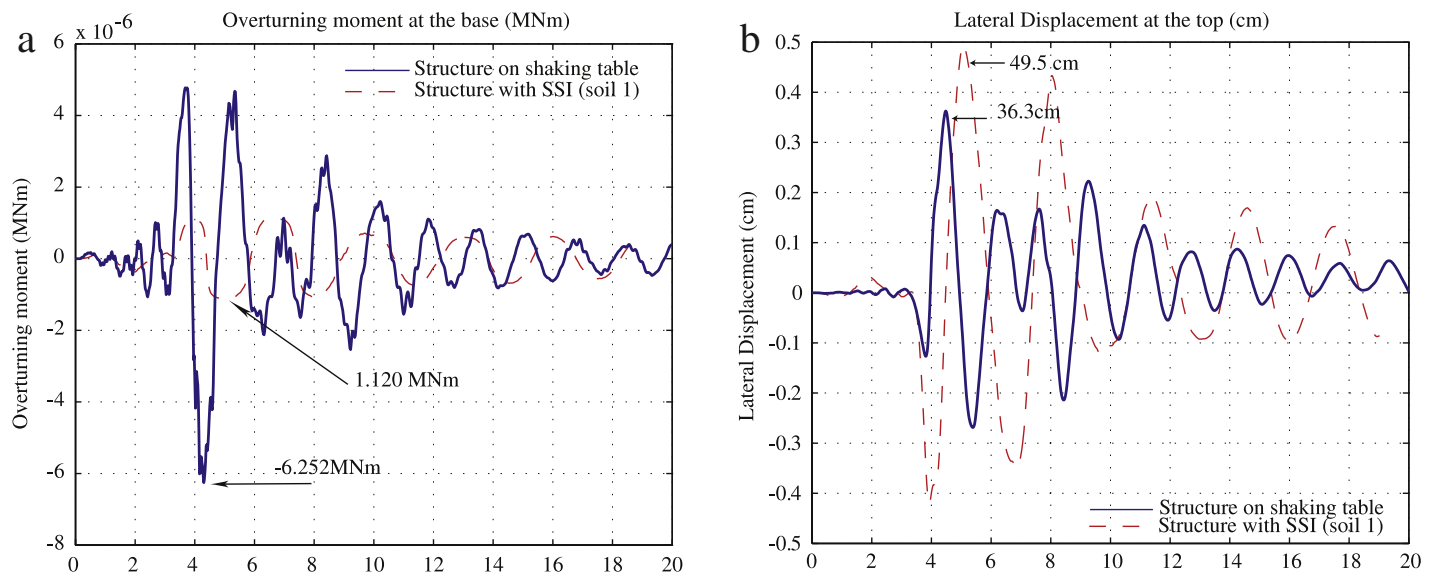

Fig. 18. NEES building (SSI numerical model): (a) Overturning moment at the base versus time and (b) lateral displacement at the top versus time for the fixed structure and the structure considering SSI (soil 1, EQ4).
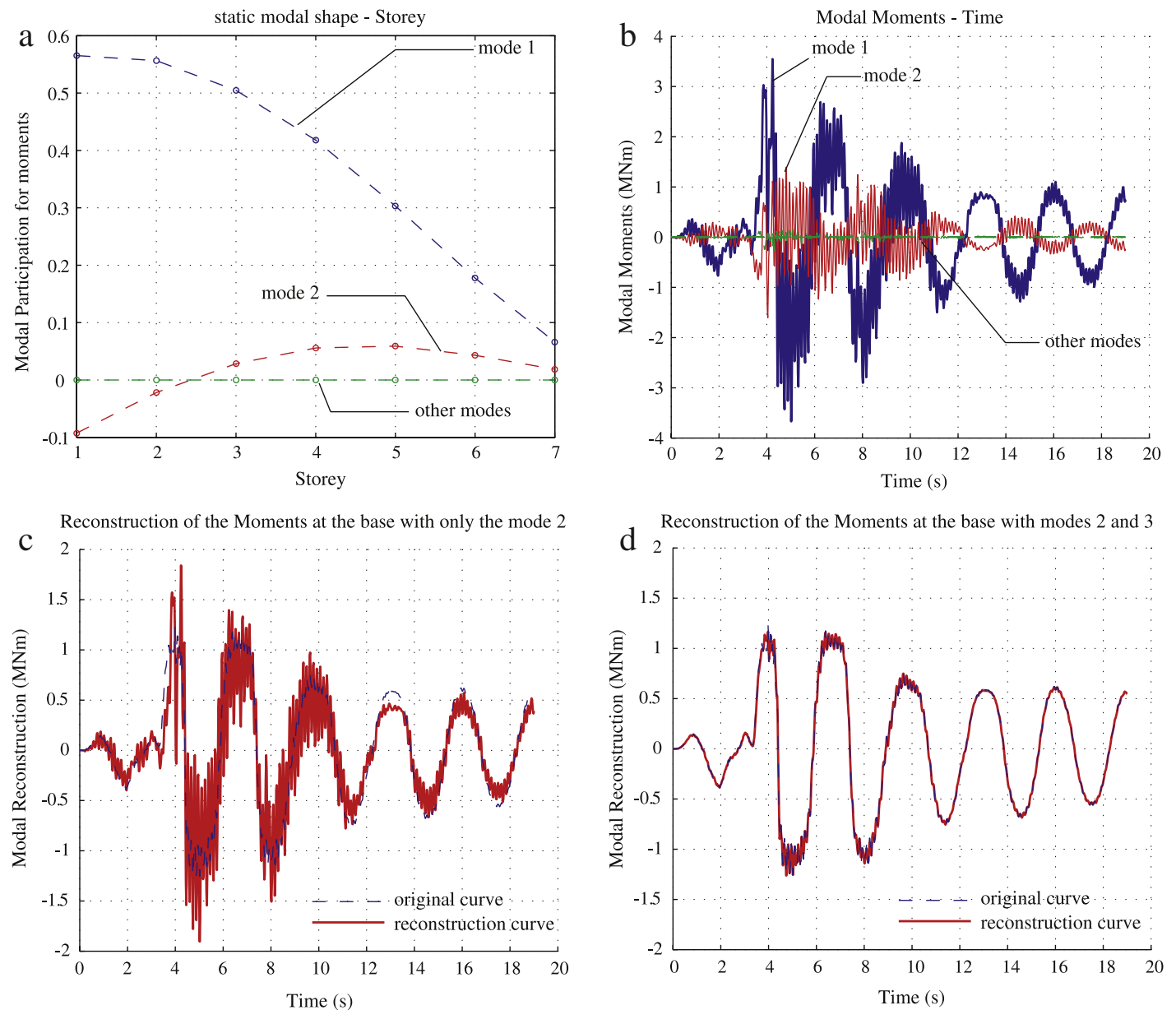

Fig. 19. NEES building (SSI numerical model): Static modal shape of the moments (a), modal moments versus time (b), reconstruction of the moments at the base of the structure considering SSI using only the first mode (c) or the first 2 modes (d) (soil 1, EQ4).

Fig. 17(a) shows the maximum overturning moments, story shears, lateral displacements, inter-story drift ratios and floor accelerations for each level. The SSI influence is compared with the numerical behavior of the original structure fixed to the shaking table ("initial structure", see also Section 6.2). The internal forces presented here (overturning moments and story shears) are calculated only at the web wall. As expected, numerical results are similar for the fixed structure and for soil 5 (class A: solid bed rock) in terms of forces and displacements. For the other cases, SSI seems to "isolate" the structure in terms of forces. Looking at Figs. 17(a), (b) and 18(a) one can observe that overturning moments and story shears are reduced. This reduction is more significant for soils with low characteristics.

Conclusions are different concerning the displacements: Fig. 17(c) shows that for soil 1, the lateral displacements at the top are lower than for soils 2 and 3. The reason is that not only the first 

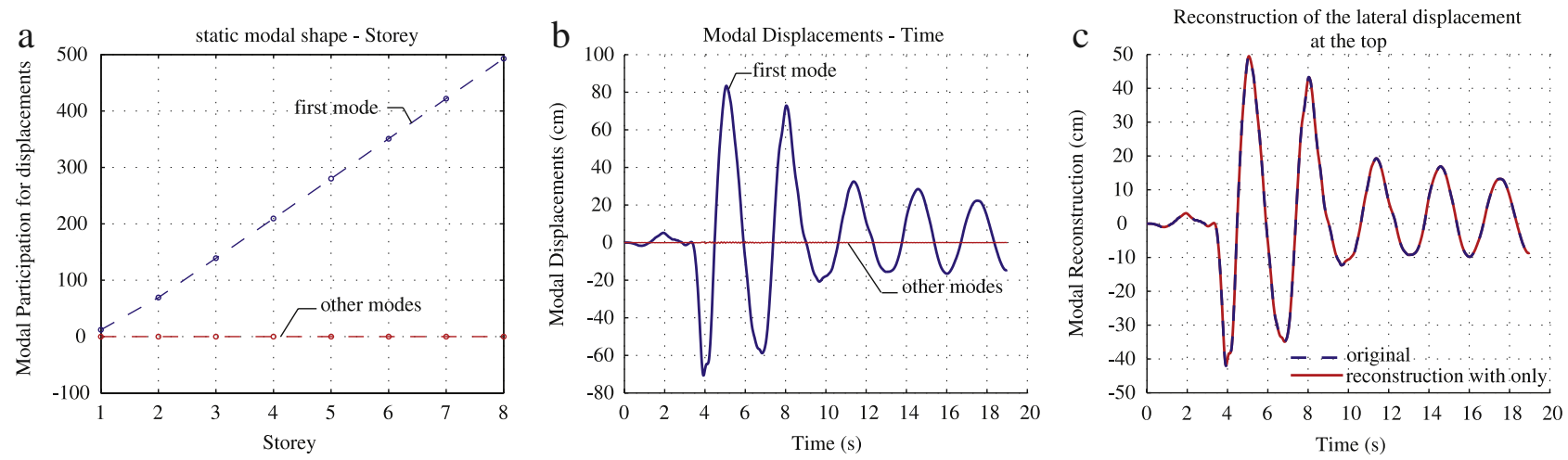

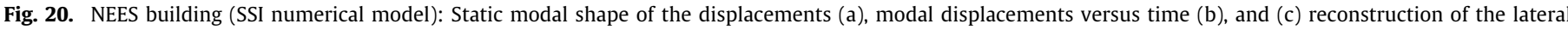
displacements at the top of the structure considering SSI (soil 1, EQ4).
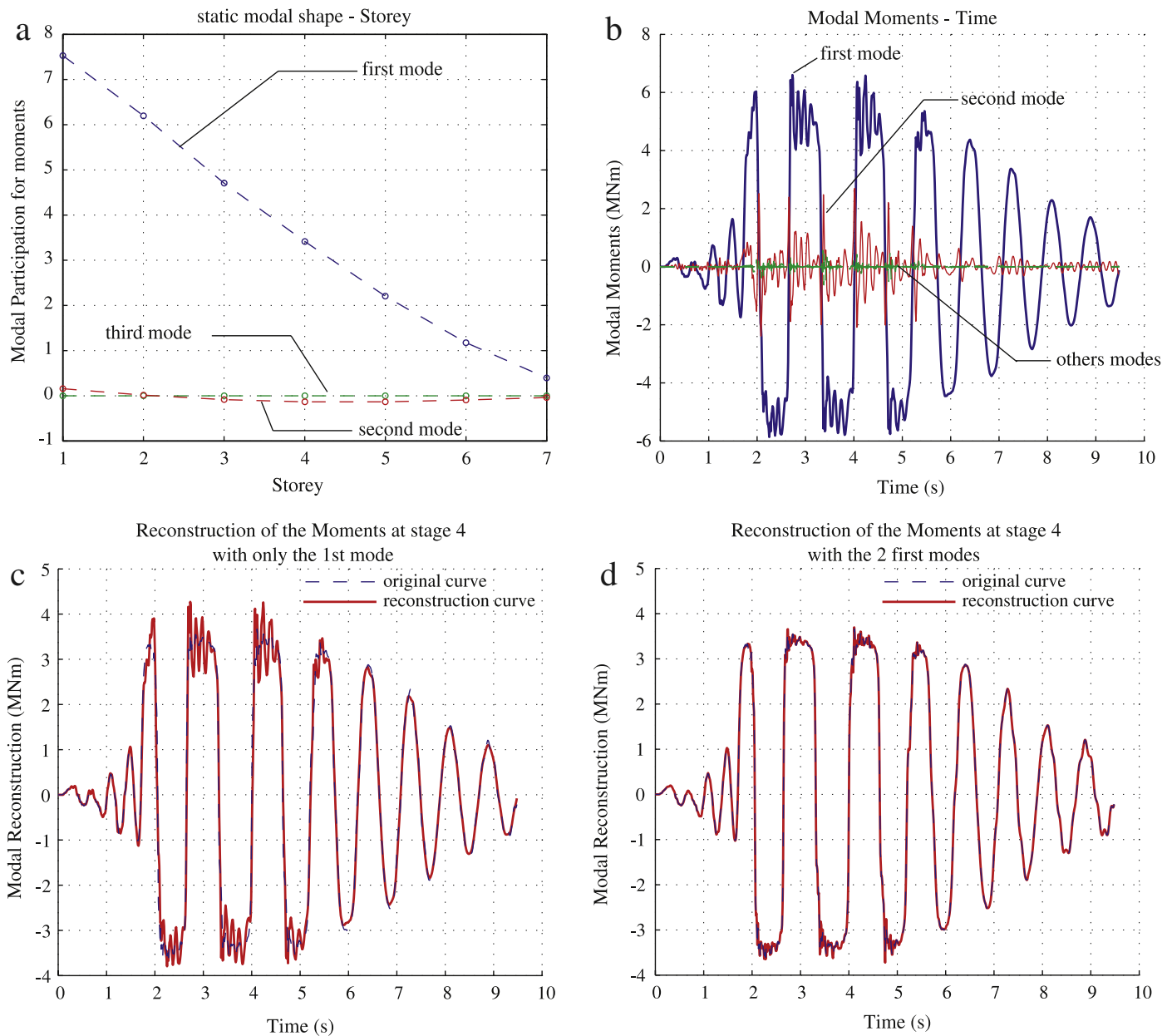

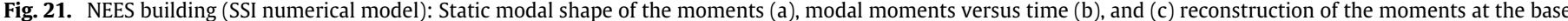
of the structure considering SSI (soil 3, EQ4).

but also the second order mode has a predominant role, modifying thus significantly the global and the local behavior of the structure. More specifically:

- In Fig. 17 it can be observed that the local behavior of the structure changes depending on the characteristics of the soil: for soil 1 numerical predictions provide the location of the maximum moment near the level 2 , not at the base of the structure.

- Both the first and the second mode influence the behavior of the structure on soil 1 in terms of the forces. This can be identified by proceeding to the modal decomposition of the moments according to the Karhunen-Loéve method [36]. Fig. 19(a) and (b) show the static modal shape, the modal participation and the time history of the modal moments (projection of the moments on the modal space) for soil 1. It is obvious that the first two modes contribute to the moments developed in the structure. This can also be verified by reconstructing the moment time history at the base of the structure. The first 2 modes are necessary to reproduce accurately the original moment time history (Fig. 19(c) and (d)). By contrast, by applying the Karhunen-Loéve method to the displacements, one can see that for soil 1 only the first mode is preponderant (Fig. 20). The 

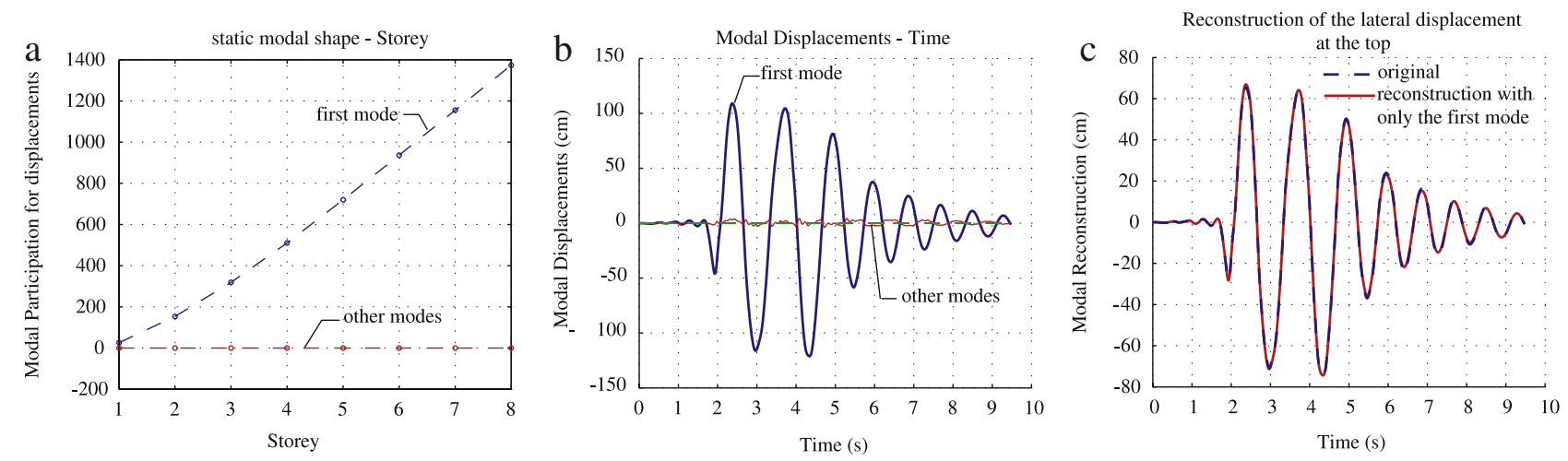

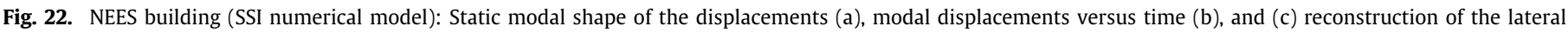
displacements at the top of the structure considering SSI (soil 3, EQ4).

deformed shape of the structure on soil 1 corresponds to the first mode on Fig. 17(c).

- Only the first mode influences the behavior of the structure on soils 2 to 5 in terms of displacements and forces (see for example Figs. 21 and 22 for the soil 3).

Fig. 17(d) shows that the inter-story drift ratio is quasi-constant for soils 1 and 2, something typical for a structure that stays elastic during the entire loading sequence. This is also verified through the distribution of the damage variable of the concrete constitutive law within the multifiber Timoshenko beam elements representing the structure: it is found everywhere equal to 0 .

Finally, it can be shown that no damage occurs in the structure for soil 1. Nonlinearities are concentrated at the interface between the foundation and the soil (due to the plasticity and the uplift). For soils 2, 3, 4 and 5, results are different, as the first 3 storeys undergo damage.

It is also found that for softer soils damage is not reduced at all levels. For the NEES structure and for the case of soil 2, it may stay high at the second story. The influence of the second mode can explain this phenomenon. Another reason is the fact that damage in traction grows more rapidly in sections where compression forces - due to the weight of the structure - are smaller (the ultimate moment is lower at the top of the structure than at lower levels).

\section{Conclusions}

In this work, we propose a simplified numerical strategy suitable for simulating dynamic Soil-Structure Interaction (SSI). After a theoretical presentation of a SSI macro-element permitting to reproduce the behavior of a rigid foundation considering uplift of the foundation and plasticity in the soil, we present in detail how the macro-element deals with $P-\theta$ effects and radiation damping according to the visco-plasticity theory.

Validation is provided through the simulations of the Camus IV structure and parametric studies on a seven-story reinforced concrete building. The macro-element is introduced at the bottom of the numerical models to simulate the influence of SSI. It is shown that SSI can isolate the structures as global forces and damage are found significantly reduced. It can also introduce a different local behavior by changing the position of the plastic hinge and by increasing the influence of the higher modes. A decrease in the stiffness of the soil does not induce necessarily an increase in the lateral displacements.

\section{Acknowledgements}

The authors are grateful for the financial support of the European Contract LESSLOSS, Risk Mitigation for Earthquakes and
Landslides of the Sixth Framework Program (Project No.: GOCE-CT2003-505488). They would also like to congratulate the organizers of the seven-story building-slice earthquake blind prediction contest and to thank them for their financial support that made possible for the 3S-R group to participate in the NEES/UCSD Workshop and Seminar "Analytical Model of Reinforced Concrete Walls" held in San Diego the 15th and 16th of December 2006.

\section{References}

[1] Cassidy MJ, Byrne BW, Houlsby GT. Modelling the behavior of circular footings under combined loading on loose carbonate sand. Géotechnique 2002;52(10): 705-12.

[2] Chatzigogos CT, Pecker A, Salençon J. Macroelement modeling of shallow foundation. Soil Dynam Earthq Eng 2009;29(5):765-81.

[3] Crémer C. Modélisation du comportement non linéaire des fondations superficielles sous séismes. Ph.D. thesis. LMT Cachan-ENS Cachan, France; 2001.

[4] Crémer C, Pecker A, Davenne L. Cyclic macro-element for soil-structure interaction: Material and geometric non-linearities. Int J Numer Anal Methods Geomech 2001;25(13):1257-84.

[5] Crémer C, Pecker A, Davenne L. Modelling of nonlinear dynamic behavior of a shallow strip foundation with macro-element. J Earthq Eng 2002;6(2): $175-211$.

[6] Di Prisco C, Nova R, Sibilia A. Analysis of soil-structure interaction of towers under cyclic loading. In: Pande GN, Pietruszczak S, editors. Invited lecture, Proc. NUMOG 8. Lisse: Swets \& Zeitlinger; 2002. p. 637-42.

[7] Di Prisco C, Galli A. Mechanical behavior of shallow foundations under cyclic loads. In: ALERT Workshop 2006 (without proceedings). Italy: Technical University (Politecnico) of Milan; 2006.

[8] Martin CM. Physical and numerical modelling of offshore foundations under combined loads. D.Phil. thesis. University of Oxford; 1994.

[9] Montrasio L, Nova R. Settlements of shallow foundations on sand: Geometrical effects. Géotechnique 1997;47(1):49-60.

[10] Nova R, Montrasio L. Settlements of shallow foundations on sand. Géotechnique 1991;41(2):243-56.

[11] Paolucci R, Pecker A. Seismic bearing capacity of shallow strip foundations on dry soils. Soils and Foundations, Japan Geotech Soc 1997;37(3):95-105.

[12] Pedretti S. Nonlinear seismic soil-foundation interaction: Analysis and modelling method. Ph.D. thesis. Dpt Ing Strutturale, Politecnico di Milano; 1998.

[13] Tan FSC. Centrifuge and theoretical modelling of conical footings on sand. Ph.D. thesis. University of Cambridge; 1990.

[14] Grange S, Kotronis P, Mazars J. A macro-element for a circular foundation to simulate 3D soil-structure interaction. Int J Numer Anal Methods Geomech 2008;32(10):1205-27.

[15] Grange S. Modélisation simplifiée 3D de l'interaction sol-structure: Application au génie parasismique. Ph.D. thesis. Laboratoire 3S-R, INP Grenoble, France; 2008. http://tel.archives-ouvertes.fr/tel-00306842/fr.

[16] Grange S, Kotronis P, Mazars J. A macro-element for a shallow foundation to simulate Soil-Structure Interaction considering uplift. C R Acad Sci Paris, Srie II b 2008;336(11-12):856-62.

[17] Grange S, Kotronis P, Mazars J. A macro-element to simulate 3D soil-structure interaction considering plasticity and uplift. Int J Solids Struct 2009;46: 3651-63. doi:10.1016/j.ijsolstr.2009.06.015.

[18] Filippou FC, Constantinides M. FedeasLab getting started guide and simulations examples. Berkeley: Dpt of civil and env. Engng. UC; 2004 
[19] CAFEEL-ECOEST/ICONS Thematic report N.5. Editors Reynouard JM, Fardis MN, editors, Severn RT and Bairrão R, gen. editors. Shear Walls Structures. (LNEC) September, 2001.

[20] Taylor CA, Combescure D. LNEC - Laboratorio Nacional de Engenharia Civil, ECOEST2, ICONS, soil dynamic and foundation structures. Rapport technique; 2001.

[21] Combescure D, Chaudat T. CEA, Direction des Réacteurs Nucléaires. Département de Mécanique et de Technologie, ICONS European program seismic tests on R/C walls with uplift; CAMUS IV specimen, ICONS project, Rapport, semt/emsi/rt/oo-27/4. 2000..

[22] NEES7story. NEES/UCSD seven-story building-slice earthquake blind prediction contest. 2006. http://nees.ucsd.edu/7Story.html.

[23] Pecker A. Analytical formulae for the seismic bearing capacity of shallow strip foundations. In: Seco e Pinto, editor. Seismic behavior of ground and geotechnical structures. Rotterdam: Balkema; 1997. p. 261-8.

[24] Simo JC, Hughes TJR. Computational inelasticity. In: Mechanics and materials. Springer interdisciplinary applied mathematics, vol. 7. 1998.

[25] Duvaut G, Lions JL. Les inéquations en mécanique et en physique. Paris: Dunod; 1972.

[26] Gazetas G. Foundations vibrations. In: Fang H-Y, editor. Foundation engineering handbook. New York: van Nostrand Reinhold; 1991 (Chapter 15).

[27] Kotronis P, Mazars J. Simplified modelling strategies to simulate the dynamic behavior of r/c walls. J Earthq Eng 2005;9(2):285-306.

[28] Mazars J, Kotronis P, Ragueneau F, Casaux G. Using multifiber beams to account for shear and torsion. Applications to concrete structural elements. Comput Methods Appl Mech Eng 2006;195(52):7264-81.

[29] La Borderie C. Phénomènes unilatéraux dans un matériau endommageable: modélisation et application l'analyse des structures en béton. Ph.D. thesis. Université Paris 6; 1991.

[30] Filippou FC, Popov EP, Bertero VV. Effects of bond deterioration on hysteretic behavior of reinforced concrete joints. Technical report EERC-83/19. Berkeley: Earthquake Engrg. Res. Ctr. Univerity of California; 1983.

[31] Menegoto M, Pinto P. Method of analysis of cyclically loaded reinforced concrete plane frames including changes in geometry and non-elastic behavior of elements under combined normal force and bending. In: IABSE symposium on resistance and ultimate deformability of structures acted on by welldefined repeated loads. Final report, Lisbon. 1973. p. 328.

[32] Grange S, Kotronis P, Mazars J. Numerical modelling of the seismic behavior of a 7-story building: NEES benchmark. Mater Struct. Online First doi:10.1617/s11527-008-9462-y, published online 27 December 2008.

[33] Davidovici V. La construction en zone sismique. France: Le Moniteur; 1999.

[34] EC8. NF P 06 030-1, NF EN 1998-1, Eurocode 8: Calcul des structures pour leur résistance aux séismes. Partie 1: Règles générales, actions sismiques et règles pour les bâtiments, AFNOR; Septembre 2005.

[35] Pecker A. Dynamique des sols. ENPC, Paris, France: Presse; 1984.

[36] Gutiérrez E, Zaldivar JM. The application of Karhunen-Loéve, or principal component analysis method, to study the non-linear seismic response of structures. Earthq Eng Struct Dyn 2000;29:1261-86. 